Doi: $\underline{\mathrm{dx} . \text { doi.org/10.17921/2525-5320.2016.316-322 }}$

\title{
SISTEMA PEDAGÓGICO DE SCHOENSTATT E SUAS CONTRIBUIÇÕES PARA EDUCAÇÃO PROFISSIONAL NA ÁREA DA SAÚDE
}

\author{
Cristina Fabricio de Melo Ghelardi* - Mater Ter Admirabilis \\ Tatiane Angélica Phelipini Borges* - Mater Ter Admirabilis \\ Irmã Elvira Maria Perides Lawand* - Mater Ter Admirabilis
}

Palavras-chave: Pedagogia de Schoenstatt. Educação Profissional. EnsinoAprendizagem.

\section{INTRODUÇÃO}

A atual conjuntura da educação, em geral, tem seguido os moldes do ensino tradicional. De um lado está o professor que é detentor do saber e do outro, o estudante que é o agente passivo de todo processo educativo. Esse método propicia que o estudante se comporte principalmente, como receptor de informações, num ambiente de subordinação e sem autonomia (KANAMARU, 2014).

No entanto, num caminho contrário a esta filosofia tradicional de ensino está o Sistema Pedagógico de Schoenstatt que oportuniza a autonomia do educando, desenvolvido pelo padre José Kentenich, fundador da Obra Internacional de Schoenstatt na década de 1910. Ele nasceu em Gymnich na Alemanha, em 16 de novembro de 1885. Como sacerdote, destacou-se por seu carisma pedagógico, sabedoria e pela clareza de objetivos e ideais. Sua obra é permeada não somente por reflexões intelectuais, mas também pelo carisma advindo pelo Espírito Santo (LAWAND, 2008).

Padre Kentenich rompeu as barreiras do sistema pedagógico tradicionalista da época, mostrando-se como uma pessoa carismática e a frente de seu tempo, especialmente pelo modo como sua metodologia era empregada, no qual priorizava o aprendizado de todos os envolvidos, incluindo-se. Segundo o Padre Kentenich, o

\footnotetext{
*E-mail: cris_ghelardi@hotmail.com

*E-mail: tatiphelipini@hotmail.com

*E-mail: diretoria.cepmta@iscal.com.br
} 
aprendizado e a autoeducação devem ser construídos em conjunto e de forma contínua, já que se tratam de processos incessantes (KENTENICH, 1997).

Inicialmente seu sistema pedagógico foi idealizado e desenvolvido para os seminaristas alemães em resposta às revoltas ocorridas pela privação de liberdade. Os estudantes estavam em clima de rebeldia e agressividade devido aos regulamentos do seminário, cujas punições não estavam surtindo o efeito esperado. Dessa forma, apostou-se que quem poderia modificador essa realidade seria um educador que teria conhecimentos pertinentes para propor resoluções viáveis (LIMA; LIMA, 1990 p.13).

Posteriormente a sua ordenação sacerdotal, Padre Kentenich retorna a este seminário para atuar como educador e desenvolver sua proposta educacional. Foi então confiado à ele, o cargo de Diretor Espiritual, no qual recebeu com seu coração, demonstrando entusiasmo e disposição para alcançar os resultados pretendidos pelo próprio Padre Kentenich e os responsáveis pela educação dos seminaristas. Sendo que o foco central seria aprender a autoeducação para projetar personalidades firmes, livres e sacerdotais, sob a proteção de Maria, Mãe do Filho de Deus que é auxílio e educadora neste caminho rumo ao coração da Santíssima Trindade (STRADA, 1989; KASTNER, 2012).

$\mathrm{Na}$ perspectiva do fundador da metodologia de Schoenstatt, a autoeducação não é somente o estudo voltado para formação profissional, mas a educação interna, um movimento de educação e de educadores. O autoeducar-se por meio da reflexão pessoal. Para educação de si próprio é primordial que o indivíduo queira, cuja linha vai ao encontro do senso comum, ou seja, a partir do momento em que o homem julga-se como um ser que tem discernimento, ele pode fazer julgamentos e escolhas de acordo com seus princípios e livre-arbítrio (LAIER, 1989).

Padre Kentenich tinha sua predileção apoiada na necessidade de formar um homem novo, no qual não se deixasse encantar por situações e palavras ilusórias, e sim, que fosse livre e tivesse autonomia para fazer suas próprias escolhas para percorrer um caminho desprendido de influências externas diretas (LAWAND, 2008).

No entendimento do fundador de Schoenstatt, um homem novo é aquele capaz de tomar decisões livre de julgamentos, prezando sua liberdade, sem, no entanto, se distanciar do amor e do respeito, além de preservar valores sociais, culturais, éticos, 
morais, políticos e religiosos. Assim, esse novo homem teria clareza o suficiente para compreender a importância do desenvolvimento também de uma nova comunidade, e de que sua personalidade influencia diretamente a sociedade (COLÉGIO MÃE DE DEUS, 2015).

Nessa perspectiva, o Sistema Pedagógico de Schoenstatt é um movimento de educação e renovação e tem por objetivo a formação de um homem novo orientado para uma nova ordem social cristã. Parte do princípio de uma metodologia educacional voltada para formação do ser humano de maneira holística, promovendo o desenvolvimento intelectual, biopsicossocial, espiritual, afetivo e ético da pessoa humana, de maneira que alie a teoria científica e a vida, cuja essência circunde o pessoal e o profissional (LAWAND, 2008; COLÉGIO MÃE DE DEUS, 2015).

O fundador do movimento de Schoenstatt aplicou sua pedagogia para educar seminaristas, apesar deste fato, seu método de ensino traz um grande direcionamento sobre educar e autoeducar, e tem sido aplicado em diversos níveis de educação, indo da educação básica até a superior. Sendo atualmente utilizada em aproximadamente 40 instituições de ensino espalhadas em diversos países (GUIMARÃES, 2007).

Sabendo que esta pedagogia abrange todos os níveis de formação, nos concentraremos na Educação Profissional, mas especificamente nos cursos Técnicos da Área da Saúde, que tem como princípio a responsabilidade de preparar a Pessoa Humana para os desafios de uma vida profissional, tanto no seu aspecto teórico como no seu propósito prático em um Centro Profissional de Ensino.

Dessa forma, teve-se a pretensão de contribuir com a disseminação de um método de educação que oferece ferramentas para enfrentar os desafios do contexto atual de ensino-aprendizagem para formação profissional e pessoal e desenvolvimento integral de seus educandos, pois não foram encontrados relatos de que o método pedagógico de Shoenstatt tenha sido implementado em cursos de nível técnico na área da saúde.

Nessa perspectiva, o objetivo desse trabalho foi o de relatar a experiência de um curso técnico da área da saúde, sob o olhar de docentes e coordenadores do 
curso que emprega a metodologia pedagógica de Schoenstatt proposto pelo Pe. Kentenich.

O Centro de Educação Profissional Mater Ter Admirabilis (CEPMTA) é um departamento da Irmandade da Santa Casa de Londrina (ISCAL), entidade hospitalar filantrópica, além de atender os campos de estágios supervisionados dos cursos ofertados.

O CEPMTA foi o primeiro centro educacional do Norte do Paraná e o segundo do Estado que iniciou a formação de auxiliares e técnicos de enfermagem. Atualmente, oferece cursos técnicos em: Enfermagem, Análises Clínicas, Podologia e Radiologia. E especializações também em nível técnico de: Urgência e Emergência, Traumatologia, Controle de Infecção Hospitalar, Unidade de Terapia Intensiva Adulta, Neonatal e Pediátrica e Enfermagem do Trabalho. Além dos cursos mencionados, o CEPMTA oferece uma ampla lista de cursos livres na área da saúde que visam complementar a formação profissional dos estudantes, alguns estendendo-se também à comunidade.

Assim, o CEPMTA alia os Pressupostos Filosóficos e Educativos propostos pela Pedagogia de Schoenstatt aos objetivos, finalidades e princípios norteadores preconizados pelas Diretrizes Curriculares Nacionais para Educação Profissional Técnica de Nível Médio descrito pelo Ministério da Educação.

Em seu contexto educacional o CEPMTA teve como gênese o Sistema Pedagógico de Schoenstatt, e seu desejo está fundamentado em formar profissionais de maneira holística, cuja formação permeia a competência técnico cientifica para que possam atuar no mundo do trabalho de forma autêntica, com conhecimento teórico-prático, sem se afastar da formação humanística e ética, não se limitando apenas ao acúmulo de conhecimento, evidenciando também, os valores cristãos, éticos e morais, seguindo a premissa do equilíbrio recomendado pelo Padre Kentenich para educação do ser humano.

Dessa forma, o processo seletivo do CEPMTA é composto por uma entrevista, no qual é oportunizado ao futuro estudante conhecer sobre o curso que pretende frequentar, e também sobre as normatizações de funcionamento do estabelecimento de ensino para que fique ciente sobre seus direitos e deveres, e para que sejam respeitados impreterivelmente, tendo como meta seu crescimento pessoal. 
O CEPMTA tem como uns de seus princípios essenciais posicionar o estudante como prioridade dentro do processo educativo, fazendo-o que se sinta parte integrante do contexto em que está inserido, e não apenas mais um estudante entre vários. Os profissionais são preparados para acolher o estudante, amparando-o em suas dificuldades e conflitos, oferecendo à ele o suporte necessário para que juntos encontrem o melhor caminho e resolução, estendendo este cuidado também aos seus familiares.

A comunicação e o diálogo são outros aspectos priorizados no CEPMTA, pois o relacionamento interpessoal é a base para boa convivência, especialmente, nos processos grupais. A escuta ativa possibilita ouvir atentamente o outro, propiciando que este também possa ouvir quando necessário. Nesse sentido, o estudante tem abertura de buscar auxílio em relação aos diferentes problemas, sejam eles particulares ou relacionados ao seu processo formador.

Nessa vertente, o emprego da Metodologia de Schoenstatt possibilita ao CEPMTA preocupar-se não somente com a formação profissional do indivíduo, mas também visa à formação pessoal e social. Mesmo sendo um curso técnico voltado para o público adulto, cuja personalidade, identidade cultural e política já estejam formadas, existem estratégias inseridas na metodologia que podem auxiliar no aprimoramento de atitudes, habilidades e virtudes pessoais, que irão valer também para vida profissional, instigando-os a agirem de modo ético e humano.

O CEPMTA mantém como hábito diário fazer uma oração antes de iniciar as aulas. Cada docente fica responsável de fazer a oração com a sua turma. Neste momento de reflexão espiritual também é levado em consideração, os diferentes credos dos alunos. Desta forma, inicialmente faz-se uma prece, e em seguida, rezase a oração universal, que é o Pai-Nosso, guardando-se o devido respeito aos estudantes que não desejam participar.

A oração auxilia no fortalecimento e resgate do lado espiritual, no qual sente-se a existência e a presença de Deus mais constantes em suas vidas. A rotina da oração eleva o ser humano ao patamar de amparo, fazendo com que se sinta mais protegido e confortado, afastando a sensação de abandono e de sentimentos que o incomodam e amedrontam, o que facilmente poderia desencadear em distúrbios 
emocionais. Ao colocar Deus no comando de sua vida, a pessoa liberta-se da ansiedade e passa ter melhor controle emocional (ESCRIBA DIGITAL, 2012).

Diante deste contexto, os profissionais que atuam no CEPMTA também são preparados para abordar e buscar os motivos pelos quais o estudante falta em dias consecutivos, ou então desiste de prosseguir no curso. Para afastar a possibilidade de ele estar se ausentando por motivos escusos à sua vontade ou por doença, e em casos passíveis de serem resolvidos, é oferecido suporte para que não abandonem o curso e deixe de lado seus sonhos.

Nesse sentido, o corpo docente percebe-se preparado para atuar de forma humanizada no ensino, pois ele também sente-se acolhido no CEPMTA, que igualmente, compartilham de seus desafios e problemas, sejam eles profissionais ou pessoais, buscando resolutividade por meio do diálogo, escuta ativa e solidariedade. Os docentes não se sentem apenas como mão de obra, e partilham do sentimento de fazerem parte de uma instituição de ensino que valoriza o ser humano em todo seu contexto biopsicossocial, oportunizando uma vivência integrada como família.

Esse cuidado para com os docentes também é permeado pelo contexto educacional, pois o CEPMTA propicia a participação destes em ações planejadas mensalmente para o aprimoramento do conhecimento, por meio da participação em cursos, educação continuada, palestras, e também possibilitando que eles ministrem cursos em empresas e similares que fazem pedido ao CEPMTA, cumprindo com sua ação social na promoção da saúde da população.

Assim, a construção em conjunto de todos os atores envolvidos no processo educacional e profissional do CEPMTA possibilitam uma edificação de saberes, no qual cada um pode desempenhar seu papel com solidez e num mesmo grau de importância dentro de um contexto de simbiose de ensino-aprendizagem. A valorização do ser humano e suas peculiaridades é a força motriz para que todos consigam aprimorar-se como ser humano para melhor atuação profissional.

A experiência adquiria ao longo dos 56 anos de fundação do CEPMTA apoiado no alicerce sólido da metodologia de Schoenstatt idealizada pelo Pe. Kentenich evidenciam que existe um acúmulo diversificado de resultados promissores no que diz respeito a colocação de profissionais qualificados no mercado de trabalho, indo 
no sentido contrário da relação de que vagas para o mercado de trabalho existem, o que está escasso são profissionais qualificados.

O mundo do trabalho está sedento por profissionais qualificados, porém que não se limitem apenas a sólidos conhecimentos e saberes, mas que também estejam preparados para os desafios que possam se deparar no cotidiano dos serviços de saúde, e ainda, que tenham arraigado em si, o cuidado humanizado e a empatia para cuidar do outro valorizando seu contexto biopsicossocial.

E é neste contexto que o CEPMTA vem se destacando, primeiro por empregar a metodologia de Schoenstatt para educação profissional de nível técnico da área da saúde, segundo, porque alia conhecimentos, saberes e competências profissionais sem se distanciar dos preceitos legal, ético, social e político para formação do novo homem para nova sociedade.

\section{REFERÊNCIAS}

COLÉGIO MÃE DE DEUS. Projeto Político Pedagógico. Instituto Social, Educativo e Beneficente Novo Signo, Colégio Mãe de Deus - Educação Infantil, Ensino Fundamental e Médio. Londrina - PR, 2015.

ESCRIBA DIGITAL. Orientações pedagógicas aos professores da EBD. 2012. Disponível em: http://euvoupraebd.blogspot.com.br/2014/04/dinamica-da-licao-05conhecendo-o-valor.html , Acesso em: 10 jun. 2016.

KANAMARU, A.T. Autonomia, cooperativismo e autogestão em Freinet: fundamentos de uma pedagogia solidária internacional. Educ. Pesq. v.40, n.3, p.767-781, 2014.

KASTNER, F. Sob a proteção de Maria: pesquisas e documentos do início da história de Schoenstatt. Santa Maria: Sociedade Mãe e Rainha, 2012.

KENTENICH, J. Minha filosofia de educação. Santa Maria-RS, 1997.

LAIER, A. Schoenstatt. Movimento de educadores e de educação. Santa Maria-RS, 1989.

LAWAND, D.; BERTAN, L. A Pedagogia de Schoenstattiana e o Colégio Mãe de Deus: contribuições para a história da educação brasileira. São Paulo: Arte Ciência, 2008.

LIMA, A.; LIMA, S. O Sistema Pedagógico de Schoenstatt. Santa Maria-RS, 1990.

STRADA, A. Maria: um exemplo de mulher. Ave Maria, São Paulo, 1989. 